\title{
ARTIGOS
}

\section{Os processos formativos de professores de inglês que trabalham na educação de jovens e adultos}

Letícia Miranda Medeiros Universidade Estadual do Rio de Janeiro - UERJ, Brasil

Helena Amaral da Fontoura Universidade Estadual do Rio de Janeiro - UERJ, Brasil

\begin{abstract}
RESUMO: A Educação de Jovens e Adultos (EJA) é uma modalidade da Educação Básica que recebe adolescentes, jovens, adultos e idosos que voltam à escola para obter certificação. Esse público merece atenção especial dos professores, pois a sala de aula da EJA reúne diversos "mundos" etários, de culturas e de experiências. Este artigo, fruto de pesquisa de Mestrado, tem o intuito de tornar evidentes os processos formativos de seis professores de Inglês da EJA, egressos daFaculdade de Formação de Professores da UERJ. Com base na tematização proposta por Fontoura, essa pesquisa qualitativa teve o propósito de investigar as trajetórias formativas desses docentes. A partir do diálogo com teóricos como Freire, Nóvoa e Gadotti, foi possível concluir que os processos formativos dos professores de Inglês não acontecem somente na educação formal, eles se estendem até o chão da escola, local onde acontecem as trocas de experiências.
\end{abstract}

PALAVRAS-CHAVE: Formação de Professores. Língua Inglesa. Educação de Jovens e Adultos.

\section{The processes of training english teachers working on youth and adult education}

\begin{abstract}
The Youth and Adults Education is a modality from basic education that receives teenagers aged over 15, youngsters, adults and elderly who return to school for certification of elementary school and/or high school. This audience deserves special attention from teachers, because this group brings together several "worlds" of age, cultures and experiences. This article, the result of a Masters research, has the intention of making evident the formative processes of six English teachers that work with EJA, graduated at Faculty of Teacher Training, Rio de Janeiro State University (UERJ). Based on the thematization proposed by Fontoura, this qualitative research had the purpose of investigating, through questionnaire and online interviews, the formative trajectories of these six English teachers who teach in this modality. From the dialogue with authors like Freire, Nóvoa and Gadotti, it was possible to conclude that the formative processes of English teachers do not happen only in formal education, they extend to inside the school, where there is sharing of experiences.
\end{abstract}

KEYWORDS: Teacher Development. English Language. Youth and Adult Education. 


\section{autêntica}

DOI https://doi.org/10.31639/rbpfp.v\%vi\%i.91

\section{INTRODUÇÃO}

Este artigo é fruto da pesquisa de (MEDEIROS, 2017) feita durante o Mestrado em Educação e tem por objetivo apresentar os processos formativos de seis professores de Inglês, egressos da Faculdade de Formação de Professores da Universidade Estadual do Rio de Janeiro, que trabalham com a Educação de Jovens e Adultos (EJA).

Com base na metodologia da tematização proposta por Fontoura (2011) que, de forma resumida, consiste em demarcar, nos depoimentos, palavras/expressões que são, de fato, relevantes para posterior análise/ reflexão e diálogo com os teóricos, este artigo pretende realizar a discussão dos processos formativos dos professores de Inglês que trabalham na Educação de Jovens e Adultos.

Foi possível traçar os perfis dos docentes por meio de questionário produzido pelo GoogleDocs e enviado online, além disso, os depoimentos dos seis professores de Inglês da EJA foram conseguidos por meio de entrevistas online, no site Facebook-Messenger e o uso desse veículo de comunicação para obter os relatos se justifica pelos estudos de Nicolaci-da-Costa; Romão-Dias e Di Luccio (2009) que salientam que há legitimidade em fazer entrevistas pela internet, quando os participantes da pesquisa usam as redes sociais com frequência e com familiaridade. Todas as entrevistas online foram realizadas após as assinaturas do Termo de Consentimento Livre e Esclarecido, que deixou claro os objetivos da pesquisa.

O propósito de investigar esses professores de Inglês está, principalmente, em delinear o processo de profissionalização que eles passaram até chegar à Educação de Jovens e Adultos (EJA). Sabe-se que a EJA é uma modalidade de ensino da Educação Básica que atende adolescentes, jovens, adultos e, até, idosos, que por diversas razões, entre elas, dificuldades financeiras, precisaram abandonar a escola por algum tempo e retornam à EJA em busca da certificação para, assim, realizar o sonho de conseguir melhor emprego, entrar na universidade, entre outros motivos.

A formação de professores para essa modalidade de ensino acontece na graduação, porém o que se nota na análise da grade curricular do curso de Letras- Português/Inglês da Faculdade de Formação de Professores da Universidade Estadual do Rio de Janeiro e que pode ser verificado em outras licenciaturas, é que o tema EJA é muito pouco discutido nos cursos que formam professores para o Ensino Fundamental II e para o Ensino Médio (MEDEIROS, 2017). Ao constatar que a disciplina Educação de Jovens e Adultos é oferecida como eletiva para os estudantes de Letras da $\mathrm{X}$ e que o tema é discutido de forma abreviada na disciplina "Estágio Supervisionado de Ensino de Língua Estrangeira III", foram feitas perguntas a esses egressos a fim de esclarecer a trajetória formativa desses seis professores de Inglês que lecionam na Educação de Jovens e Adultos.

\section{OS PARTICIPANTES DA PESQUISA - PERFIL DOS EGRESSOS DE INGLÊS}

Após fazer as entrevistas e analisar as respostas do questionário, foi possível conhecer os perfis dos seis egressos, participantes desta pesquisa, que, de agora em diante, serão nomeados como Docente 1, Docente 2, Docente 3 e assim por diante, para salvaguardar o anonimato dos mesmos. 


\section{autêntica}

DOI https://doi.org/10.31639/rbpfp.v\%vi\%i.91

No quadro 1 é possível ver os perfis pessoais e acadêmicos dos seis participantes desta pesquisa. Eles estão na faixa etária entre 28 e 40 anos (idade referente ao ano de 2017) e apenas um professor é do sexo masculino.

QUADRO 1 - PERFIS ACADÊMICOS DOS DOCENTES DE INGLÊS, PARTICIPANTES DESTA PESQUISA

\begin{tabular}{|c|c|c|c|c|c|}
\hline & Sexo & Idade & $\begin{array}{c}\text { Ano de conclusão } \\
\text { da Graduação }\end{array}$ & $\begin{array}{c}\text { Curso de } \\
\text { ítulo de Pós-Graduação } \\
\text { atualização } \\
\text { recente }\end{array}$ \\
\hline Docente 1 & F & 40 & 2000 & $\begin{array}{c}\text { Concluindo a } \\
\text { Especialização }\end{array}$ & Sim \\
\hline Docente 2 & F & 39 & 1999 & NÃO & Sim \\
\hline Docente 3 & F & 28 & 2010 & Mestrado & Sim \\
\hline Docente 4 & F & 39 & 2001 & Especialização (360h) & Sim \\
\hline Docente 5 & F & 40 & 2000 & Mestrado & Sim \\
\hline Docente 6 & M & 30 & 2012 & Curso de extensão (30h) & Sim \\
\hline
\end{tabular}

Fonte: Dados oriundos das respostas do questionário.

A característica predominantemente feminina na docência, segundo Gadotti (2007), revela a força da profissão, pois a mulher tem exercido "um papel cada vez mais protagonista, inserindo-se, cada vez mais, na vida social, política e econômica das sociedades mais avançadas. A participação da mulher na sociedade é indicador de avanço social e de desenvolvimento humano" (GADOTTI, 2007, p.26). Décadas atrás, ser professora era a única opção para as moças que queriam percorrer o campo intelectivo e laboral, porém, atualmente, visto que há inúmeras carreiras, escolher a profissão docente pode ser também questão de vocação e de prazer no ato educativo.

Além dessa característica de sexo, apontada por Moacir Gadotti, o autor segue reconhecendo que os professores ganham mal, como ele mesmo escreve, "somos profissionais de baixa renda". Grandes perdas se multiplicam por conta dessa característica, como a dificuldade na compra de livros, baixa frequência a teatros, cinemas, museus, visitas a outras cidades e países, etc. Porém, como diz o autor ao concordar e citar o sociólogo, professor e político brasileiro Florestan Fernandes, somos 'os debaixo' e por termos essa característica de oprimidos, apresentamos "um potencial revolucionário que outras profissões não têm, já que é uma profissão voltada para a emancipação das pessoas" (GADOTTI, 2007, p.27). Laura Miccoli (2016), ao escrever sobre a valorização do ofício de professor, lembra que, ao considerar tudo o que um professor faz, é impossível medir o valor desse profissional pelo salário que ele recebe e acrescenta:

Sob esse ponto de vista, nenhuma professora teria valor, pois a importância dos frutos de seu trabalho é materialmente imensurável. Afinal, como se paga a alguém que cria as condições para que outro alguém realize, invente, crie ou faça algo que promoverá a vida de outros? É isso que um professor faz (MICCOLI, 2016, p. 35).

Cabe sublinhar que as Docentes 3 e 5 relataram que já concluíram o Mestrado. A Docente 4 possui curso de Especialização em Língua Inglesa e o Docente 6 tem curso de extensão. Apesar de terem se formado há quase 20 anos, a Docente 2 não concluiu nenhum curso de Pós-Graduação e a Docente 1 está em fase de 


\section{autêntica}

DOI https://doi.org/10.31639/rbpfp.v\%vi\%i.91

conclusão de um curso de Especialização em Língua Inglesa. Convém ressaltar que todos os participantes desta pesquisa relataram que fizeram cursos de atualização recentemente.

Com as respostas do questionário, foi possível delinear também os perfis profissionais dos participantes desta pesquisa, a saber:

\section{QUADRO 2 - PERFIS PROFISSIONAIS DOS DOCENTES DE INGLÊS, PARTICIPANTES DESTA PESQUISA}

\begin{tabular}{|c|c|c|c|c|c|}
\hline & $\begin{array}{c}\text { Anos de } \\
\text { docência } \\
\text { em Inglês }\end{array}$ & $\begin{array}{c}\text { Quantidade de } \\
\text { instituições em } \\
\text { que trabalha }\end{array}$ & $\begin{array}{c}\text { Carga horária } \\
\text { semanal }\end{array}$ & $\begin{array}{c}\text { Anos de } \\
\text { docência } \\
\text { na EJA }\end{array}$ & $\begin{array}{c}\text { Municípios em } \\
\text { que trabalha } \\
\text { com a EJA }\end{array}$ \\
\hline Docente 1 & 16 a 20 & Mais de 4 & $50 h$ & 11 a 15 & Araruama e Macaé \\
\hline Docente 2 & 16 a 20 & 2 & $32 h$ & 6 a 10 & São Gonçalo \\
\hline Docente 3 & 6 a 10 & 2 & $32 h$ & 2 a 5 & São Gonçalo \\
\hline Docente 4 & 16 a 20 & Mais de 4 & $40 h$ & 6 a 10 & Niterói \\
\hline Docente 5 & 16 a 20 & 2 & $32 h$ & 6 a 10 & Niterói \\
\hline Docente 6 & 6 a 10 & 3 & $40 h$ & 2 a 5 & Magé \\
\hline
\end{tabular}

Fonte: Dados oriundos das respostas do questionário.

No quadro 2, apresentado acima, é possível perceber que todos os docentes participantes desta pesquisa trabalham em mais de uma escola, têm carga horária semanal de trabalho de no mínimo 32 horas, lecionam Inglês há mais de seis anos e trabalham com a Educação de Jovens e Adultos (EJA) há mais de 2 anos, em municípios do Estado do Rio de Janeiro.

Um dado que chama bastante a atenção está justamente nas informações dadas pela Docente 1, que se formou na FFP, no ano de 2000. É possível perceber que ela tem uma carga horária de trabalho semanal bem extensa ( 50 horas) e trabalha em mais de 4 instituições; além disso, ela informou que trabalha em dois municípios diferentes com a Educação de Jovens e Adultos (Araruama e Macaé), seu tempo livre é escasso e se resume a deslocamento de uma escola para outra, trânsito, planejamento de aulas, correções de testes e provas, tempo para família e para si.

Com isso, é possível observar que, para ter um salário digno e poder sustentar a família, os profissionais da educação precisam se revezar entre duas ou mais escolas, com uma carga horária de trabalho pesada, o que faz com que o tempo e a disposição para o estudo fiquem bastante reduzidos. Ao escrever sobre a jornada exaustiva do professor, Ana Barcelos (2016) afirma que as condições de trabalho são estressantes e prejudicam o ânimo para estudar além das aulas que ele precisa ministrar. "Muitos professores trabalham em duas ou três escolas e dão mais de 40 horas/aula por semana, lidando com trezentos alunos ou mais de manhã, à tarde, à noite. Muitos vivem estressados e fatigados" (BARCELOS, 2016, p. 42).

Os dois quadros acima, compostos a partir das respostas ao questionário, mostram os perfis acadêmicos e profissionais dos participantes desta pesquisa e ajudam a tornar pública a necessidade de investimentos na carreira docente. Acerca dessa questão, Freire (1996) faz um alerta. 


\title{
autêntica
}

DOI https://doi.org/10.31639/rbpfp.v\%vi\%i.91

\begin{abstract}
Se há algo que os educandos brasileiros precisam saber, desde a mais tenra idade, é que a luta em favor do respeito aos educadores e à educação inclui que a briga por salários menos imorais é um dever irrecusável e não só um direito deles. A luta dos professores em defesa de seus direitos e de sua dignidade deve ser entendida como um momento importante de sua prática docente, enquanto prática ética (FREIRE, 1996, p.39)
\end{abstract}

Essa recomendação de Freire endossa a luta que os profissionais de educação vêm travando há décadas para ter salários mais dignos e deixa claro que conscientizar os alunos sobre o respeito e a valorização dos professores é muito mais que um direito dos docentes, é obrigação de toda a sociedade.

Cabe ressaltar aqui que investir no professor é papel não só dos sistemas de educação - ao proporcionar cursos de atualização e progressão salarial aos seus professores, ou das universidades - ao oportunizar vagas em cursos de extensão e Pós-Graduação (especialização, mestrado, doutorado) para continuar capacitando os professores da Educação Básica; vale lembrar que o investimento principal cabe aos próprios professores que, por meio da busca incessante por novos conhecimentos e abordagens de ensino e cientes de que são seres em formação, se matriculam em cursos e se envolvem em debates na própria escola e em fóruns virtuais para compartilhar práticas e se apropriar de novas aprendizagens. Como diz Lucas (2016), é importante que o professor continue investindo em sua formação, por meio de participação em eventos e encontros com colegas da área, pois os compartilhamentos de experiências e de conhecimentos contribuem para o desenvolvimento da prática educativa.

Ao iniciar a entrevista, a pergunta sobre o motivo da escolha pela docência emergiu e a influência profissional da família foi fator determinante, como relataram os docentes 4,5 e 6 .

Docente 4: Bem, cresci em um ambiente escolar, visto que a minha casa era literalmente uma escola primária idealizada e desenvolvida por minha mãe. Vislumbrei desde cedo o fascínio pela Educação. Meus pais também são professores e pessoas que sempre admirei.... Creio, portanto, que tudo isso colaborou para despertar em mim a vontade de ser professora.... Sempre considerei o magistério uma profissão especial

Docente 5: Desde criança admiro essa profissão e sempre tive facilidade com as disciplinas Português e Inglês. Minha mãe é professora e a escola era um ambiente que eu gostava. Quando chegou a época de escolher a profissão, minha primeira escolha foi pelo curso de Direito, mas não passei no vestibular, depois optei pelo curso de Letras e passei para FFP/UERJ. Identifiquei-me como o curso e com as disciplinas oferecidas e, desde o terceiro período, leciono Língua Inglesa na escola básica.

Docente 6: Posso dizer que foi por ciclo vicioso. Tenho mãe e avó professora. E acabei sendo também.

Os demais professores pesquisados relataram que a razão da escolha do curso de Letras foi a paixão pelo Inglês e pelo ensino dessa língua.

Docente 1: Para ser sincera, eu queria ser veterinária, mas não tinha como pagar. E, como eu passei como segunda opção para Letras, achei que depois, trabalhando, teria como pagar a faculdade. Porém, me apaixonei pela profissão. 


\section{autêntica}

DOI https://doi.org/10.31639/rbpfp.v\%vi\%i.91

Docente 2: Eu sempre dizia na infância que iria ser professora, mas o fator determinante foi a língua inglesa. Eu queria fazer algum curso onde eu pudesse usar o inglês, então escolhi Letras.

Docente 3: Ajudei um amigo profissionalmente com algumas traduções e para ensiná-lo comecei a buscar métodos e estudar diferentes metodologias. Me identifiquei, abandonei ciências contábeis e comecei a fazer Letras.

Quando indagados se o passado escolar teve influência na escolha do curso de Letras-Português/Inglês, os elogios aos professores de Inglês da Educação Básica e também dos cursos de idiomas foram observados em quase todos os depoimentos.

Docente 1: Eu fazia curso de inglês e a mesma professora me dava aulas na escola e no curso, ela fez eu gostar da língua.

Docente 2: Tive alguns professores que marcaram minha vida escolar. Foram bons exemplos.

Docente 3: Eu tive uma professora no curso de inglês que ensinava maravilhosamente bem e fazia tudo com muito amor.

Docente 4: Ter uma boa formação escolar, com verdadeiros exemplos de profissionais fez-me admirar cada vez mais a profissão e querer isso para mim também!

Já a Docente 5 sinalizou que escolheu ser professora por gostar do ambiente escolar e o Docente 6, como transcrito abaixo, relatou que escolheu o curso, pois o objetivo era ser tradutor e intérprete, mas o contato com as disciplinas de Educação e os estágios o fizeram trilhar os caminhos da docência.

Docente 6: Me apaixonei pelo inglês quando tinha 15 anos e desde então minha vida passou ao foco de aprender a língua. Com isso comecei a fazer o curso. Me interessei depois em fazer letras para ser tradutor ou intérprete. Mas passei pra FFP. Logo o magistério ficou muito mais perto de mim. Daí pra ser um professor de inglês e fazer concurso pro magistério foi um pulo.

Magda Chamon (2011) aponta que a escolha pela docência pode ser feita justamente pela descoberta dos desafios e do prazer do fazer educativo e acrescenta que é no exercício da profissão que os educadores passam a ser protagonistas e podem agir por meio de práticas coletivas a fim de favorecer "a compreensão das construções sociais e dos ordenamentos político-econômicos da sociedade que interferem negativamente nos processos educativos, para, neles, intervirem em favor da garantia do direito à educação de qualidade para aqueles a quem é negada" (CHAMON, 2011, p.79). Direito esse que corrobora com a principal luta dos professores e pesquisadores da EJA, o princípio da educação para todos, instituído no artigo 205, da Constituição Brasileira (BRASIL, 1988).

Ao investigar os participantes desta pesquisa sobre como chegaram/permaneceram na Educação de Jovens e Adultos, a maioria relatou que ao passar no concurso da rede Estadual ou Municipal, no ato da escolha de turmas, eles foram direcionados ao trabalho com a EJA, por conta de ser o único horário disponível.

Docente 2: Quando fui chamada pelo Estado na minha segunda matrícula não tinha muitas opções de escolas. Então, escolhi o turno da noite porque era o único horário que não batia com minha outra escola. Só quando me apresentei que soube que se tratava de EJA.Gostei de trabalhar com jovens e adultos. Descobri alunos interessados em aprender. 


\title{
autêntica
}

DOI https://doi.org/10.31639/rbpfp.v\%vi\%i.91

\begin{abstract}
Docente 5: Após passar para o concurso de professores do Estado do RJ, em 2005, fui alocada em uma escola no turno da manhã, mas logo me ofereceram turmas no horário da noite, com turmas de jovens, adultos e também alguns poucos idosos. [...] O público, apesar de ser bastante diversificado, com presença de diferentes faixas etárias, é bom de se trabalhar. É um grande aprendizado, uma troca de saberes. Eu ensino um pouco da Língua Inglesa e também aprendo com as vivências deles, com a bagagem que eles trazem.
\end{abstract}

Docente 6: Trabalho na prefeitura de Magé. Assim que cheguei na escola. A diretora me ofereceu 3 turmas de EJA. O horário era interessante. Aceitei a oferta. E já tinha trabalhado com EJA antes também na prefeitura do Rio.

A Docente 1 relatou que começou a trabalhar com a EJA, após ter aceitado trabalhar à noite, em uma área perigosa, depois da recusa de outros professores; a Docente 3 teve seu primeiro contato com essa modalidade de ensino quando resolveu aceitar turmas da EJA para aumentar a renda e a Docente 4 iniciou o trabalho com a EJA na rede privada de ensino. Os extratos abaixo retratam esse início do trabalho com essa modalidade de ensino.

Docente 1: No início de carreira, tinha contrato em uma escola estadual em Itaboraí, numa área que era considerada perigosa e ninguém queria trabalhar à noite. Como eu precisava trabalhar, aceitei a oportunidade. Desde então, trabalho todos os anos com a EJA.

Docente 3: Comecei trabalhando no Ensino Regular e tive a oportunidade de dar umas aulas extras na EJA, a pedido da direção escolar.... Acabei amando o público jovem e adulto e transferi minha matricula para o turno da noite, para trabalhar só com a modalidade EJA.Sou completamente apaixonada pela EJA e defensora! É um público cativante.

Docente 4: Quando comecei a dar aula à noite em uma escola particular e depois no Estado. Porque fui trabalhar no CEJA, me identifiquei com o trabalho realizado na escola e na possibilidade em alcançar os alunos muito além da minha disciplina. Eles precisam de orientação, um olhar diferenciado e respeito por estudar e tentar uma vida profissional melhor. [...] Porque é um ensino diferenciado e o horário permanecia bom pra mim.

A maioria dos participantes desta pesquisa, com exceção da Docente 4, começou a lecionar na Educação de Jovens e Adultos não por escolha, mas por necessidade de ajuste do horário e todos relataram a urgência em buscar conhecimentos para o trabalho com essa modalidade, seja por meio de cursos de atualização, seja trocando experiências com os colegas.

\section{OS PROCESSOS FORMATIVOS DOS PROFESSORES DE INGLÊS DA EJA, EGRESSOS DA FFP/UERJ}

A formação em serviço é a engrenagem que impulsiona a concretização de uma escola para todos e não apenas para crianças e adolescentes, ela também oxigena as práticas educativas, trazendo novas reflexões a partir da leitura de teóricos e da troca de vivências. Conforme Maria Santos (2011, p.151), a formação em serviço "é necessária a cada professor, no coletivo da troca interativa de experiências", porque, de fato, a escola do século XXI precisa estar apta a acolher e saber lidar com as diferenças etárias e de culturas. Marcelo (2009) declara que o conhecimento e os alunos são as matérias-primas com que os professores trabalham e para "continuar a dar uma resposta adequada ao direito de aprender dos alunos, teremos de fazer um esforço redobrado para continuar a aprender" (MARCELO, 2009, p.8). Como o autor mesmo salienta, 


\section{autêntica}

DOI https://doi.org/10.31639/rbpfp.v\%vi\%i.91

"o desenvolvimento profissional docente pode ser entendido como uma atitude permanente de indagação, de formulação de questões e procura de soluções" (MARCELO, 2009, p.9). Os processos formativos, portanto, vão se consolidando à medida que o professor ganha experiência e busca por mais conhecimentos.

Assim, os processos formativos acontecem não só na universidade ou em cursos de formação, pois "o professor é formado por processos sucessivos de reflexão sobre a ação. Essa reflexão reverte-se em uma ação renovada pela reflexão. [...] Professor reflexivo trabalhando na formação de um aluno crítico e reflexivo" (CLARETO, 2011, p. 57). Desse modo, é na ação pedagógica que se dá a reflexão acerca da incompletude do profissional, e se desponta na necessidade de aperfeiçoamento constante.

Igualmente, Pires, Alves e Gonçalves (2016, p.60) concordam que é necessário que "os docentes atualizem as suas competências para desempenharem eficazmente o seu papel ao longo da vida profissional". Essas atualizações podem ocorrer em cursos formais, de forma coletiva (em conversas com outros colegas) ou de forma individual, na leitura de um livro, na observação e posterior reflexão de uma aula. Trata-se, portanto, de uma busca incessante por soluções para facilitar a aprendizagem.

Bognar, Moura e Silva (2015) realçam que a formação continuada em serviço contribui com a ação educativa para que se construam novas pedagogias e abordagens apropriadas aos educandos jovens e adultos. Os autores compreendem a educação como prática para o desenvolvimento da cidadania e salientam que "é imprescindível que os professores tenham tempo e as condições necessárias para a formação continuada próximo de sua realidade escolar e dos problemas sentidos e vivenciados por eles" (BOGNAR; MOURA; SILVA, 2015, p. 15).

O Brasil, por meio da Lei de Diretrizes e Bases da Educação Nacional (Lei no. 9.394/96), evidencia essa preocupação com a atualização constante dos professores e determina que é de incumbência das redes de ensino promover o aperfeiçoamento dos seus profissionais, garantindo-Ihes um período reservado a estudos.

Art. 67. Os sistemas de ensino promoverão a valorização dos profissionais da educação, assegurando-lhes, inclusive nos termos dos estatutos e dos planos de carreira do magistério público: I - ingresso exclusivamente por concurso público de provas e títulos; || - aperfeiçoamento profissional continuado, inclusive com licenciamento periódico remunerado para esse fim; III - piso salarial profissional; IV - progressão funcional baseada na titulação ou habilitação, e na avaliação do desempenho; $V$ - período reservado a estudos, planejamento e avaliação, incluído na carga de trabalho; VI - condições adequadas de trabalho (BRASIL, 1996).

Gadotti (2007) lembra que a formação em serviço é um direito do professor e salienta que, para que a lei seja cumprida na prática, é necessário respeitar algumas exigências, que o autor assim classifica:

$1^{\text {a }}$ direito a pelo menos 4 horas semanais de estudo com os colegas, não só com especialistas de fora, para refletirem sobre a sua própria prática, dividirem dúvidas e resultados obtidos; $2^{\circ}$ possibilidade de frequentar cursos sequenciais aprofundados em estudos regulares, sobretudo sobre o ensino das disciplinas ou campos do conhecimento de cada professor; $3^{\circ}$ acesso à bibliografia atualizada; $4^{\circ}$ possibilidade de sistematizar sua experiência e escrever sobre ela; $5^{\circ}$ possibilidade de participar e expor sua experiência em congressos educacionais; $6^{\circ}$ possibilidade de publicar a experiência sistematizada; $7^{\circ}$ enfim, não só sistematizar e publicar suas reflexões, mas também colocar em rede essas reflexões, o que cada professor, cada professora, cada escola está fazendo, 


\section{autêntica}

DOI https://doi.org/10.31639/rbpfp.v\%vi\%i.91

por exemplo, através de uma site da secretaria de educação ou da própria escola (GADOTTI, 2007, p. 36-37).

Gadotti (2007) acredita, assim como Freire, que defendia o diálogo crítico como essência da educação, que a formação de professores tem o poder de educar para a humanidade, cooperação, esperança e possibilidades.

Ciente da lei acima citada (BRASIL, 1996), uma das questões da entrevista, feita aos participantes desta pesquisa, foi justamente indagar se a rede de ensino a que eles têm prestado serviço oferece curso de atualização voltado para o público com que eles trabalham. As Docentes 1, 2 e 5 relataram que fizeram um curso online voltado paras as especificidades da EJA, porém tiveram experiências diferentes, como atestam os fragmentos abaixo.

Docente 1: Sim. A Rede Estadual, online. Era [um curso] específico para o EJA, com o nome de EDUCAÇÃO PARA JOVENS E ADULTOS mesmo. Não conclui, pois não havia suporte por parte deles e várias perguntas ficaram sem respostas. Como não estava me acrescentando em nada, parei.

Docente 2: Sim, já ofereceu a formação continuada. Foi voltado pra EJA dentro do novo padrão de módulos que foi adotado pelo Estado do Rio de Janeiro. Na verdade, o material desenvolvido pela rede estadual de ensino não está dentro da realidade do alunado da EJA. Mas o curso valeu pela troca de experiências com outros colegas e em como adaptar o material para os nossos alunos.

Docente 5: Sim. Fiz o curso NEJA (Nova Educação de Jovens e Adultos) ofertado para professores que trabalhavam com o Ensino Médio. Esse curso era voltado para orientação dos professores acerca do novo material que chegaria à escola para ser utilizado com os alunos. Com esse novo sistema, o Ensino Médio do Estado do RJ passou a ser oferecido em 4 semestres letivos e a Língua Inglesa passou a ser oferecida somente no último semestre.O curso contribuiu muito para reflexão sobre minha prática, com leitura de textos que apresentaram suporte para melhorar a abordagem de ensino e propor melhorias ao meu fazer pedagógico.

Não se sabe ao certo o motivo pelo qual as docentes participantes tiveram impressões diversas sobre o mesmo curso online, porém é possível tirar algumas conclusões. Como o curso foi oferecido para todos os professores da EJA da rede Estadual do Rio de Janeiro, e pelo fato delas trabalharem em municípios diferentes (Docente 1 - Araruama e Macaé; Docente 2 - São Gonçalo e Docente 5 - Niterói), possivelmente elas tiveram tutores diferentes e participaram de salas virtuais distintas para troca de experiências.

Ao tratar da questão da formação continuada de professores, Gadotti (2007) salienta que esta deve desenvolver um padrão colaborativo e de cooperação entre os professores. O autor ainda destaca que

A formação do profissional da educação está diretamente relacionada com o enfoque, a perspectiva, a concepção mesma que se tem da sua formação e de suas funções atuais. Para nós, a formação continuada do professor deve ser concebida como reflexão, pesquisa, ação, descoberta, organização, fundamentação, revisão e construção teórica e não como mera aprendizagem de novas técnicas, atualização em novas receitas pedagógicas ou aprendizagem das últimas inovações tecnológicas (GADOTTI, 2007, p. 33).

Analisando mais atentamente o fragmento da fala da Docente 2, que diz: "O material desenvolvido pela rede estadual de ensino não está dentro da realidade do alunado da EJA", uma outra questão vem à tona, que é 


\section{autêntica}

DOI https://doi.org/10.31639/rbpfp.v\%vi\%i.91

o livro didático. Esse assunto é muito discutido entre os linguistas e professores da área e, como observa Patrícia Lucas (2016), quem planeja o livro, na maioria das vezes, está longe da sala de aula e desconhece a realidade dos estudantes. Portanto, cabe aos professores incluir os alunos e as suas necessidades e fazer as adaptações necessárias com o material que se está trabalhando.

Por maior que seja a massificação do consumo, por mais que se tente padronizar as relações entre as pessoas - e talvez por uma reação natural ao que é impingido - mais as pessoas, incluindo os aprendizes, sentem-se no direito de exigir um tratamento personalizado, que leve em consideração não só suas necessidades, mas também seus interesses. $\mathrm{O}$ atendimento a esses dois aspectos - necessidades e interesses - não pode ser feito através do uso de materiais que são produzidos em massa; é preciso no mínimo uma adaptação do material já existente pelo professor, embora a melhor solução seja produzir o próprio material (LEFFA, 2001, p.13).

De acordo com Lucas (2016), uma das prioridades no planejamento das aulas de Inglês continua sendo os estudantes e seus interesses. Nesse viés, concordamos com Leffa (2001), é importante que o material de ensino seja desenvolvido ou adaptado de acordo com as necessidades do grupo de alunos.

Para tanto, faz-se necessário que o professor invista em sua formação, seja participando de eventos, congressos, seja compartilhando experiências de sala de aula e conhecimentos. O fato é que a formação docente, além de necessária, precisa priorizar a reflexão crítica sobre a prática. A participação em cursos de atualização tem sido comum entre os demais participantes desta pesquisa, eles também relataram que já se envolveram em cursos voltados para o público da EJA.

Docente 3: Sim! Mais recentemente fiz um minicurso na Secretaria de Educação de SG voltado para os professores da EJA. Participei também de um curso sobre EJA profissionalizante.

Docente 4: Sim.Já fiz alguns cursos de capacitação para o uso de um material específico, tecnologias, novas práticas pedagógicas e tópicos ligados à psicologia e motivação.

Docente 6: Já. [...] A rede ofereceu no sentido de anunciar. Não custear.

Assim, percebe-se, com as falas dos professores, ao se engajarem em cursos de atualização, o alto nível de comprometimento que todos os participantes desta pesquisa têm com as suas carreiras e principalmente com o público com que vêm trabalhando. Ao tratar do tema formação de professores, Figueiredo (2011) evidencia que "é neste lugar que o professor avança no modo de produzir a sua ação e assim, vai transformando a sua prática" (p.144). A autora ainda salienta que os cursos de formação docente precisam considerar as singularidades, as práticas, os contextos e a história de vida de cada profissional para que eles possam refletir sobre as competências necessárias para uma atuação pedagógica mais acolhedora.

Quando questionados se procuram participar de cursos de atualização por conta própria, todos os participantes responderam positivamente. Destaca-se a fala da Docente 3, formada no ano de 2010 e que trabalha no município de São Gonçalo. De tão engajada com seus processos formativos, listou, durante a entrevista, alguns dos cursos que fez nos últimos anos.

Docente 3: Curso de revitalização dos professores de Língua Inglesa do EF do RJ (fiz esse várias vezes); Treinamento em Metodologia e Técnicas para o Ensino de Inglês como Língua Estrangeira para o Ensino Fundamental I e Ensino Fundamental II; Curso de Aprender a Aprender: Contribuições da Teoria Social Cognitiva para Prática Pedagógica; Espaço da Universidade na Sociedade.; Práticas 


\section{autêntica}

DOI https://doi.org/10.31639/rbpfp.v\%vi\%i.91

Pedagógicas na Diversidade; Encontro de Experimentação do projeto Oi Kabum! Imagine-se reunindo memórias. Fiz muitos cursos.... Está faltando muito.

A participação em cursos de atualização proporciona encontros com outras realidades e contextos, descobertas de novas abordagens e ambientes de cooperação, de reflexão e de novos conhecimentos. A necessidade da formação em serviço é confirmada por vários teóricos (NÓVOA, 1992; GADOTTI, 2007; MARCELO, 2009), porém, para que ela seja efetiva, precisa construir no ideário dos professores "novas pedagogias e métodos de trabalho apropriados aos educandos. Este é um desafio colocado ao docente que precisa lidar com a diversidade existente nessa modalidade" (BOGNAR; MOURA; SILVA, 2015, p. 2).

Ao investigarmos se os cursos de atualização (seja com o tema EJA ou não) foram significativos para o trabaIho com a Educação de Jovens e Adultos, os participantes da pesquisa concordaram que o tempo separado para reflexão trouxe renovação e muito aprendizado.

Docente 3: Sim. Participar desses cursos permitiu ampliar conhecimentos na área e estar em contato com outros profissionais (não apenas da EJA), compartilhando experiências e agregando valores e novas aprendizagens.

Docente 4: Sim. Mesmo que não tenha sido específico a EJA, aprender ou debater novas práticas em educação sempre me leva a reflexão do meu próprio trabalho, a realidade e necessidades dos meus alunos e o que eu consigo fazer naquele espaço físico.

Docente 5: Com certeza, pois ler artigos de especialistas da EJA, entre outros autores de educação, permitiu-me um novo olhar sobre esse público. Além disso, fez-me repensar as aulas e considerar os alunos e sua bagagem, além de suas expectativas, para escolha de conteúdos a serem abordados.

Docente 6: Sim. Foi. Porque os prismas da educação que se aprende nunca são descartáveis. Tudo se reaproveita. Embora o foco do curso que fiz tenha sido no ensino fundamental regular, muita coisa deu pra aproveitar pro EJA. A forma das aulas práticas, métodos de ensino e mais coisas.

Nóvoa (1992) acredita que o momento de diálogo entre os professores consolida saberes, cria redes de trabalho e é um fator primordial de socialização profissional. Assim a formação em serviço tende a apresentar novidade de modos de trabalho pedagógico que levam à reflexão crítica para novas práticas educativas.

Nessa direção, sobre a importância da formação dos professores da EJA, Tania Moura (2009) reforça que escolarizar jovens e adultos não é apenas ter como apoio uma análise crítica da realidade social, vai mais além, é preocupar-se com a ressocialização do trabalhador, levando-o a desvelar a realidade a ponto de encontrar soluções para os problemas; para tal é imprescindível ter profissionais em permanente formação.

Entende-se que as políticas e ações governamentais deveriam garantir a formação básica e continuada de educadores de jovens e adultos. Os currículos dos cursos Normais e das Licenciaturas precisam contemplar a formação específica desses profissionais de forma que eles tenham acesso a saberes gerais e específicos numa relação teoria-prática que dê conta das peculiaridades socioculturais e pedagógicas dos jovens e adultos trabalhadores (MOURA, 2009, p. 64). 


\section{autêntica}

DOI https://doi.org/10.31639/rbpfp.v\%vi\%i.91

Temos vivido na era da informação, o conhecimento se altera de forma veloz, assim como a forma de aprender e ensinar. Desse modo, optar por ser professor e continuar a trilhar a carreira docente é fazer a opção pelo aprendizado constante, aprender novas formas de ensinar e ensinar os alunos a aprender, a pesquisar e a compartilhar saberes. Como destaca Marcelo (2009), o desenvolvimento profissional dos professores é um processo individual e coletivo que acontece principalmente na escola e que traz contribuições para "o desenvolvimento das suas competências profissionais, através de experiências de índole diferente, tanto formais como informais" (MARCELO, 2009, p. 07).

Os processos formativos dos participantes desta pesquisa revelam a preocupação dos mesmos com a meIhoria de sua prática pedagógica e nos faz concordar com os escritos de Freire (1996) quando diz que nós somos inacabados e precisamos tecer redes de influências para construir práticas significativas.

\section{ALGUMAS CONSIDERAÇÕES}

Uma conclusão que se pode tirar, após trabalhar com os achados da pesquisa, é que a educação formal (graduação, cursos de extensão, especialização, mestrado, doutorado) não consegue abranger todas as peculiaridades que a escola apresenta hoje. A formação do professor é realmente um processo, seu ponto de partida são as lembranças do tempo da escola, quando foi estudante da Educação Básica; logo depois, toma forma quando se escolhe fazer um curso de licenciatura e, em certa medida, os processos formativos dos professores perduram até a aposentadoria. Laura Miccoli (2016) lembra que a participação em cursos de atualização não basta para melhorar o ensino e a aprendizagem.

\footnotetext{
Um bom professor se faz na prática, pois formação alguma o prepara para a imprevisibilidade da sala de aula. Melhorar não significa, apenas, fazer cursos. Pode, num primeiro passo, ser resultado de conversas com colegas sobre como obter um melhor desempenho. Refletir, pensar novas possibilidades de ação, testá-las e avaliar resultados para compreender melhor a aprendizagem dos alunos (MICCOLI, 2016, p.36)
}

É possível afirmar, portanto, que a formação inicial proporcionou subsídios para o trabalho com a matéria-prima da EJA, que são os alunos. Entretanto, a inserção na prática de ensino com os jovens e adultos, o processo colaborativo com os outros professores e os cursos de atualização de que os docentes participaram são os ingredientes que, de fato, proporcionaram reflexão e aprimoramento no ato de ensinar para esse público.

É notório que o professor está sempre em formação, independente dos cursos dos quais participa. De certa forma, o docente está envolvido em processo de formação quando planeja, quando avalia, quando se reúne com a equipe pedagógica, quando escuta as necessidades dos alunos e quando volta para casa refletindo nos pontos positivos e negativos da aula que acabou de ser ministrada.

Portanto, foi possível notar com os relatos dos participantes desta pesquisa que eles percebem que a formação é contínua e que esta extrapola a educação formal. Além da participação em cursos de atualização, os seus processos formativos acontecem na troca de experiências com os colegas, nas conversas com os seus alunos e na busca por um ensino emancipatório e significativo. 


\section{autêntica}

DOI https://doi.org/10.31639/rbpfp.v\%vi\%i.91

\section{REFERÊNCIAS}

BARCELOS, Ana Maria Ferreira. "I can do it!": vencer limitações pessoais no uso do Inglês. In: CUNHA, Alex Garcia; MICCOLI, Laura (orgs.). Faça a diferença: ensinar Línguas Estrangeiras na Educação Básica. São Paulo: Parábola Editorial, p. 38-47, 2016.

BOGNAR, Ivana; MOURA, Jefferson Bento; SILVA; Osvaldo Pereira da Cunha. Tempos e espaços na formação continuada dos educadores de EJA: uma saída possível. Anais. V Seminário Nacional. Formação de Educadores de Jovens e Adultos. São Paulo, Campinas: Unicamp. 13 a 15 de maio de 2015. Disponível em: <http://sistemas3.sead.ufscar.br/snfee/index.php/snfee/article/viewFile/114/34>. Acesso em: 18 ago. 2017.

BRASIL. Constituição Federal. Constituição da República Federativa do Brasil de 1988. Brasília, DF: Senado, 1988. $140 \mathrm{p}$.

Lei de Diretrizes e Bases da Educação Nacional, n 9394, de 20 de dezembro de 1996.

CHAMON, Magda. O instituído e o instituinte nos cursos de formação de professores: desafios da contemporaneidade. Formação Docente, Belo Horizonte, v. 03, n. 04, p. 71-80, jan./jul. 2011. Disponível em:<http:// formacaodocente.autenticaeditora.com.br>. Acesso em: 21 mar. 2017.

CLARETO, Sônia Maria. Como alguém aprende a ser professor? Políticas cognitivas, aprendizagem e formação do professor. In: FONTOURA, Helena Amaral e SILVA, Marco (orgs). Formação de Professores, Culturas: desafios à Pós-graduação em Educação em suas múltiplas dimensões. Rio de Janeiro: ANPEd Nacional, p.50-61, 2011. Disponível em: <http://www.fe.ufrj.br/anpedinha2011/livro2.html. . . Acesso em: 30 set. 2016.

FIGUEIREDO, Rita Vieira de. A formação de professores para a inclusão dos alunos no espaço pedagógico da diversidade. In: MANTOAN, Maria Teresa Eglér (org.). O desafio das diferenças nas escolas. Petrópolis, RJ.Vozes, p.141-145, 2011.

FONTOURA, Helena Amaral da. Tematização como proposta de análise de dados na pesquisa qualitativa. In: FONTOURA, Helena Amaral da (Org.) Formação de professores e diversidades culturais: múltiplos olhares em pesquisa. Niterói: Intertexto, p. 61-82, 2011.

FREIRE, Paulo. Pedagogia da autonomia: saberes necessários à prática educativa. São Paulo: Paz e Terra, 1996.

GADOTTI, Moacir. Boniteza de um sonho: ensinar-e-aprender com sentido. Campos dos Goytacazes, RJ: WTC Editora, 2007.

LEFFA, Vilson José. A linguística aplicada e seu compromisso com a sociedade. In: Anais - VI Congresso Brasileiro de Linguística Aplicada. Belo Horizonte: UFMG, 7-11 de outubro de 2001. Disponível em: <http:// www.leffa.pro.br/textos/trabalhos/la_sociedade.pdf>. Acesso em: 15 de jun. 2017.

LUCAS, Patrícia de Oliveira. Materiais didáticos x interesses necessidades: considerações sobre as fantasias dos aprendizes no planejamento de um curso de Línguas. In: BARBIRATO, Rita de Cássia; SILVA, Vera Lucia Teixeira da. (Orgs.) Planejamento de cursos de línguas: traçando rotas, explorando caminhos. Campinas, SP: Pontes, 2016. 


\section{autêntica}

DOI https://doi.org/10.31639/rbpfp.v\%vi\%i.91

MARCELO, Carlos. Desenvolvimento Profissional Docente: passado e futuro. Sísifo. Revista de Ciências da Educação, n. 08, p. 7-22, jan.-abril, 2009.

MEDEIROS, Letícia Miranda. Processos formativos de docentes de Inglês que trabalham na Educação de Jovens e Adultos: estudo com egressos da Faculdade de Formação de Professores da Universidade do Estado do Rio de Janeiro. 2017. 116 f. Dissertação (Mestrado em Educação) - Faculdade de Formação de Professores, Universidade do Estado do Rio de Janeiro, São Gonçalo, 2017.

MICCOLI, Laura. Valorizar a disciplina de Inglês e seu trabalho de professor. In: CUNHA, Alex Garcia; MICCOLI, Laura (orgs.). Faça a diferença: ensinar Línguas Estrangeiras na Educação Básica. São Paulo: Parábola Editorial, p. 14-36, 2016.

MOURA, Tania Maria de Melo. Formação de educadores de jovens e adultos: realidade, desafios e perspectivas atuais. Práxis Educacional, Vitória da Conquista, v. 5, n. 7 p. 45-72, jul./dez., 2009. Disponível em: <http://periodicos.uesb.br/index.php/praxis/article/viewFile/242/254>. Acesso em: 31 mar. 2017.

NICOLACI-DA-COSTA, Ana Maria; ROMÃO-DIAS, Daniela e DI LUCCIO, Flávia. Uso de Entrevistas On-line no Método de Explicitação do Discurso Subjacente (MEDS). Psicologia: Reflexão e Crítica, 22(1), p. 36-43, 2009.

NÓVOA, Antônio. Formação de professores e profissão docente. 1992. Disponível em: <http://repositorio. ul.pt/bitstream/10451/4758/1/FPPD_A_Novoa.pdf>. Acesso em: 10 maio de 2016.

PIRES, Rui; ALVES, Mariana Gaio; GONÇALVES, Teresa N. R. Desenvolvimento profissional docente: percepções dos professores em diferentes períodos ao longo da vida. Revista Portuguesa de Pedagogia. ANO 50-1, p. 57-78, 2016.

SANTOS, Maria Terezinha da Consolação Teixeira dos. Inclusão escolar: desafios e perspectivas. In: MANTOAN, Maria Teresa Eglér (org.). O desafio das diferenças nas escolas. Petrópolis, RJ: Vozes, p. 147-152, 2011. 